\title{
How Technological Advances Can Reveal Rights
}

\author{
Jack Parker \\ Carnegie Mellon University \\ cgparker@andrew.cmu.edu
}

\section{ACM Reference Format:}

Jack Parker and David Danks. 2019. How Technological Advances Can Reveal Rights. In AAAI/ACM Conference on AI, Ethics, and Society (AIES '19), January 27-28, 2019, Honolulu, HI, USA. ACM, New York, NY, USA, 1 page. https://doi.org/10.1145/3306618.3314274

Over recent decades, technological development has been accompanied by the proposal of new rights by various groups and individuals: the right to public anonymity, the right to be forgotten, and the right to disconnect, for example. Although there is widespread acknowledgment of the motivation behind these proposed rights, there is little agreement about their actual normative status. One potential challenge is that the claims only arise in contingent social-technical contexts, which may affect how we conceive of them ethically (albeit, not necessarily in terms of policy). What sort of morally legitimate rights claims depend on such contingencies?

Our paper investigates the grounds on which such proposals might be considered "actual" rights. ${ }^{1}$ We propose the notion of a revealed right, a right that only imposes duties - and thus is only meaningfully revealed - in certain technological contexts. Our framework is based on an interest theory approach to rights, which understands rights in terms of a justificatory role: morally important aspects of a person's well-being (interests) ground rights, which then justify holding someone to a duty that promotes or protects that interest. Our framework uses this approach to interpret the conflicts that lead to revealed rights in terms of how technological developments cause shifts in the balance of power to promote particular interests.

Different parties can have competing or conflicting interests. It is also generally accepted that some interests are more normatively important than others (even if only within a particular framework). We can refer to this difference in importance by saying that the former interest has less "moral weight" than the latter interest (in that context). The moral weight of an interest is connected to its contribution to the interest-holder's overall well-being, and thereby determines the strength of the reason that a corresponding right provides to justify a duty. Improved technology can offer resources that grant one party increased causal power to realize its interests to the detriment of another's capacity to do so, even while the relative moral weight of their interests remain the same.

\footnotetext{
${ }^{1}$ The full paper can be found at http://www.andrew.cmu.edu/user/cgparker/Parker Danks_RevealedRights.pdf.

Permission to make digital or hard copies of all or part of this work for personal or classroom use is granted without fee provided that copies are not made or distributed for profit or commercial advantage and that copies bear this notice and the full citation on the first page. Copyrights for components of this work owned by others than the author(s) must be honored. Abstracting with credit is permitted. To copy otherwise, or republish, to post on servers or to redistribute to lists, requires prior specific permission and/or a fee. Request permissions from permissions@acm.org.

AIES '19, January 27-28, 2019, Honolulu, HI, USA

(C) 2019 Copyright held by the owner/author(s). Publication rights licensed to ACM. ACM ISBN 978-1-4503-6324-2/19/01 . \$ \$15.00

https://doi.org/10.1145/3306618.3314274
}

\author{
David Danks \\ Carnegie Mellon University \\ ddanks@cmu.edu
}

Such changes in circumstance can make the importance of protecting a particular interest newly salient. If that interest's moral weight justifies establishing a duty to protect it, thereby limiting the threat posed by the new socio-technical context, then a right is revealed. Revealed rights justify realignment between the moral weight and causal power orderings so that people with weightier interests have greater power to protect those interests.

In the extended paper, we show how this account can be applied to the interpretation of two recently proposed "rights": the right to be forgotten, and the right to disconnect. Since we are focused on making sense of revealed rights, not any particular substantive theory of interests or well-being, the characterization of 'weights' is a free parameter in this account. Our framework alone cannot provide means to resolve the question of whether specific rights exist, but it can be used to identify empirical questions that need to be answered to decide the existence or non-existence of such rights. The emergence of a revealed right depends on a number of factors, including: whether the plausible uses of the technology could potentially impede another's well-being or interests; whether the technology is sufficiently common to have a wider, social impact; and whether the technology has actually changed the balance of power sufficiently to yield a frequent possibility for misalignment between causal power and moral weight.

This approach confronts the question of how, in principle, such rights could be justified, without requiring specific commitments on the ontology of rights. Our account explains why the rhetoric of "new rights" is both accurate (since the rights were not previously recognized) and inaccurate (since the rights were present all along, but without corresponding duties). Further, it explains the rights without grounding their normative status in considerations related to right-holders' capacities to rationally waive or assert claims. This is especially important given that many of the relevant disruptive technological developments pose challenges to understanding by affected parties for the same reasons they pose threats to those parties' well-being. In the course of our discussion, we confront a number of potential objections to the account. We argue that our framework's ability to accommodate highly specific or derivativeseeming rights is un-problematic. We also head off worries that our use of interest theory makes the account likely to recognize absurd rights claims.

\section{ACKNOWLEDGMENTS}

This paper was made possible in part by a grant from Carnegie Corporation of New York. David Danks is the recipient of an Andrew Carnegie Fellowship. The statements made and views expressed are solely the responsibility of the authors. 